\title{
Pengembangan Prototype Sistem Kendali Kualitas Air Tambak Udang
}

\author{
Avara Ghamaliel Ty ${ }^{1}$, Pramudi Utomo ${ }^{2}$ \\ 1,2Program Studi Teknik Elektronika Fakultas Teknik Universitas Negeri Yogyakarta \\ E-mail: avara.ghamaliel2015@student.uny.ac.id
}

\begin{abstract}
The purpose of this article is to describe the analysis, design and performance of prototype shrimp water quality control systems. This tool is expected to simplify and ease the work of shrimp farmers in checking water quality regularly. In its design consists of several steps, namely designing the design of tools, making mechanical systems, programming, and the final stage of testing. The main component that is used as the main control is Arduino Nano. Salinity sensor, DS18b20, and PH-4520C as components for monitoring water quality. 12V DC water pump as a stabilizer of the $\mathrm{pH}$ level in the water. Based on the results of testing the average error for the water temperature sensor, water pH sensor and salinity sensor are $0.74 \%, 2.06 \%$, and 3.60\%, respectively. The three error values are less than 10\%. Based on the results of testing the $\mathrm{pH}$ of water, liquid pH up will be sprayed when the $\mathrm{pH}$ value of the water is less than 6.5. While the liquid $\mathrm{pH}$ down will be narrowed when the pH value of water is less than 8. The results of this performance test can work in accordance with the function and purpose.
\end{abstract}

Keywords: control system, water quality, arduino nano, shrimp ponds

\begin{abstract}
ABSTRAK
Tujuan artikel ini untuk mendeskripsikan analisis, perancangan dan unjuk kerja prototipe sistem kendali kualitas air tambak udang. Alat ini diharapkan dapat mempermudah dan meringankan pekerjaan petambak udang dalam pengecekan kualitas air secara berkala. Dalam perancangannya terdiri dari beberapa langkah yaitu mendesain rancangan alat, membuat sistem mekanik, pemrograman, dan tahap terakhir melakukan pengujian. Komponen utama yang digunakan sebagai kontrol utama adalah Arduino Nano. Sensor Salinitas, DS18b20, dan PH-4520C sebagai komponen untuk memonitoring kualitas air. Pompa air DC 12V sebagai penstabil kadar pH di dalam air. Berdasarkan hasil pengujian rata-rata error untuk sensor suhu air, sensor $\mathrm{pH}$ air dan sensor salinitas berturut-turut adalah $0.74 \%, 2.06 \%$, dan $3.60 \%$. Ketiga nilai error tersebut kurang dari $10 \%$. Berdasarkan hasil pengujian pengendalian $\mathrm{pH}$ air, cairan $\mathrm{pH}$ up akan disemprotkan ketika nilai $\mathrm{pH}$ air kurang dari 6.5. Sedangkan cairan $\mathrm{pH}$ down akan disempotkan ketika nilai $\mathrm{pH}$ air kurang dari 8. Hasil pengujian unjuk kerja ini dapat bekerja sesuai dengan fungsi dan tujuannya.
\end{abstract}

Kata kunci: sistem kendali, kualitas air, arduino nano, tambak udang

\section{PENDAHULUAN}

Udang merupakan salah satu komoditas ekspor unggulan yang perlu ditingkatkan baik dari segi kualitas dan kuantitasnya di Indonesia. Menurut Permana, udang pada dasarnya hidup di laut, namun ada beberapa jenis udang yang juga hidup di air tawar [1]. Udang yang banyak diproduksi atau dihasilkan oleh masyarakat antara lain adalah udang windu, udang putih dan udang dogol. Udang yang berpotensial tinggi untuk dibudayakan dalam tambak adalah udang windu dan udang putih atau vaname. Kedua udang ini mampu untuk menoleransi kadar garam air antar $0 \%-45 \%$. Udang vaname adalah jenis udang yang berasal dari air payau dan tidak membutuhkan kadar garam yang terlalu tinggi. Kadar garam yang dapat ditoleransi oleh udang vaname agar tetap merasa nyaman adalah pada kisaran $10-20 \%$ maka pertubuhan udang dapat maksimal. Untuk kisaran kadar garam 10 - 35\% udang masih dapat bertahan hidup, tumbuh, dan berkembang namun pertumbuhan tersebut mungkin tidak akan terlalu optimal. 
Nilai ekspor udang vaname (Litopenaeus Vannamei) beku sebesar $27 \%$ pada total nilai ekspor perikanan tahun 2016 [2]. Hal tersebut menunjukkan bahwa udang memiliki peranan yang sangat besar dalam bidang ekonomi perikanan di Indonesia [2]. Disamping memiliki keunggulan kompetitif, komoditas udang di Indonesia memiliki daya saing yang tidak kuat di pasar Eropa, sehingga peningkatan daya saing perlu dilakukan, salah satunya melalui pemeliharaan udang yang tepat [3]. Sebagian besar kegagalan budidaya udang vaname terjadi pada proses pembesaran, salah satunya karena dipengaruhi oleh kualitas air media pemeliharaan yang menyebabkan munculnya beberapa penyakit [4]. Komponen utama agar dapat bertahan hidup untuk berternak udang vaname adalah air sebagai media hidupnya.

Kondisi lingkungan dalam tambak menjadi salah satu permasalahan yang utama dikarenakan kebutuhan hidup udang sangat bergantung pada lingkungan tambak. Kondisi lingkungan tambak terkait erat dengan kualitas air pada tambak udang yang terdiri dari beberapa parameter yaitu salinitas $10-10-33 p p t$, suhu $26^{\circ} \mathrm{C}$ sampai dengan $30^{\circ} \mathrm{C}$, DO (Dissolved Oxygen) 47.5ppm, derajat keasaman $(\mathrm{pH})$ 6.5-8. Namun parameter yang paling penting yang menyebabkan kematian udang adalah salinitas, $\mathrm{pH}$ dan suhu oleh sebab itu harus dipantau setiap hari.

Masalah yang sering dihadapi oleh petambak udang adalah tingkat kualitas air yang buruk atau belum sesuai kriteria untuk budidaya udang yang maksimal. Hal ini yang dapat menyebakan tingkat kematian budidaya udang sangat besar dan berdampak gagal panen. Pada budidaya udang, salah satu kendala bagi para petambak udang adalah cara dalam melakukan pengecekan kualitas air yang masih menggunakan metode manual. Dengan pengecekan kualitas air yang tidak berkalala atau terus menerus ini dapat mengakibatkan perubahan mendadak pada kualitas air tanpa diketahui oleh petambak udang sehingga berdampak buruk pada proses budidaya udang dan mengakibatkan petambak gagal panen.
Beberapa parameter kualitas air tambak yang perlu dipantau diantaranya terkait kecerahan, suhu, salinitas, oksigen terlarut, amoniak, nitrit, alkalinitas, BOD, $\mathrm{pH}$ dan plankton [5]. Pengendalian kualitas lingkungan melalui penerapan teknologi merupakan salah satu hal perlu mendapat perhatian [6]. Melihat dari permasalahan yang ada maka dibuatlah suatu alat, harapannya akan diaplikasikan pada tambak udang guna mempermudah kualitas air ditambak udang.

\section{METODE}

Tahap Identifikasi dan Analisis Kebutuhan

Tahap desain/ perancangan sistem

Tahap pembuatan perangkat

\section{Tahap pengujian}

Gambar 1. Tahapan pengembangan perangkat

Pembuatan prototype sistem kendali kualitas air dengan menggunakan Arduino Nano ini dirancang agar dapat memonitoring dan mengendalikan kualitas air. Pada pembuatannya, dibutuhkan beberapa langkah untuk merancang sistem yaitu: (1) diperlukan kebutuhan komponen melalui identifikasi dan analisis kebutuhan; (2) mendesain rancangan alat; (3) membuat sistem mekanik dan pemrograman; dan (4) tahap terakhir melakukan pengujian alat sehingga didapatkan hasil alat dengan kinerja yang akurat sesuai dengan apa yang diharapkan. Tahapan tersebut sesuai dengan Gambar 1. Pada tahap pengujian fungsional, dianalisis nilai error pengukuran. Rumus 1 merupakan rumus prosentase error. Rumus 2 merupakan rumus rerata error.

$$
\begin{gathered}
\text { error }(\%)=\frac{\text { nilai sensor }- \text { nilai pembanding }(\text { standar })}{\text { nilai pembanding }(\text { standar })} \times 100 \% \text { (1) } \\
\text { rata }- \text { rata error }(\%)=\frac{\sum \text { error }}{\sum \text { uji coba }}(2)
\end{gathered}
$$




\section{HASIL DAN PEMBAHASAN}

Realisasi prototype sistem kendali kualitas air tambak udang ini membutukan beberapa komponen yaitu, (1) Arduino Nano, (2) Sensor pH air, (3) Sensor salinitas air, (4) Sensor suhu air, (5) Motor servo, (6) Relay, (7) Pompa air, (8) Power supply 12V 5A, (9) LCD, (10) RTC, dan (11) Buzzer. Berdasarkan identifikasi kebutuhan di atas, maka diperoleh beberapa analisis kebutuhan terhadap sistem yang akan dirancang adalah sebagai berikut: (1) Arduino, dimana alat ini membutuhkan komponen yang dapat mengolah data dari masukan yang akan dikirim ke bagian keluaran. Pada proses ini Arduino Nano digunakan sebagai pengendali utama yang akan melakukan pemrosesan dan pengendali sistem data. Arduino Nano dipilih sebagai pengendali utama karena memiliki 14 buah pin digital yang dapat digunakan untuk jalur input maupun output yang sifatnya dapat di program ulang (Programmable); (2) Catu daya $12 \mathrm{~V} 5 \mathrm{~A}$ sebanyak dan modul step down sebanyak 1 buah. Power supply digunakan untuk mensuplai daya pada pompa air DC dan Arduino Nano. Modul step down digunakan untuk menurunkan tegangan $12 \mathrm{~V}$ dari power supply menjadi 5V ke Arduino Nano; (3) relay 2 kanal digunakan untuk mengontrol pompa air DC yang membutuhkan $12 \mathrm{~V}$. Relay yang digunakan menggunakan kemampuan hantar arus sebesar 5A; (4) pompa air DC digunakan untuk menyemprotkan suatu cairan $\mathrm{pH}$ up dan $\mathrm{pH}$ down pada tambak udang sebagai pengatur tingkat keasaman air. Pompa air DC ini dapat bekerja dengan daya $9-14 \mathrm{~V}$; (5) sensor ph air sebagai perangkat yang digunakan untuk mendeteksi tingkat keasaman air dalam tambak kemudian diproses dalam bentuk data pada Arduino Nano; (6) Sensor Suhu Air sebagai perangkat yang digunakan untuk mendeteksi suatu suhu air dalam tambak kemudian diproses dalam bentuk data pada Arduino Nano; (7) Sensor salinitas sebagai perangkat yang digunakan untuk mendeteksi tingkat kadar garam dalam tambak kemudian diproses dalam bentuk data pada Arduino Nano; (8) motor servo sebagai mekanik penggerak pergantian pembacaan pada sensor salinitas dan sensor $\mathrm{pH}$ air; (9) LCD untuk menampilkan pembacaan data suatu sensor-sensor pada tambak udang; (10) RTC digunakan sebagai pengatur waktu pada alat ini; dan (11) Buzzer sebagai alarm pada alat monitoring jika kualitas air buruk.

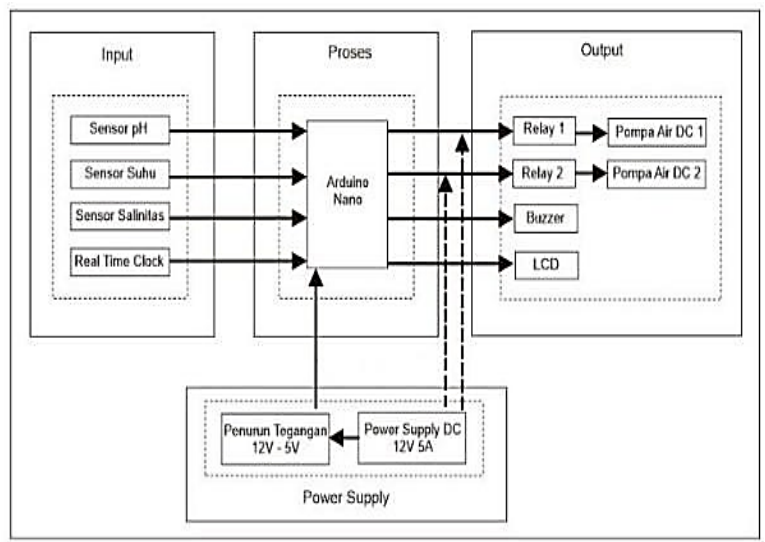

Gambar 2. Diagram rangkaian

Gambar 2 merupakan blok diagram dari alat monitoring dan pengendalian kualitas air tersebut. Blok power supply merupakan blok yang berisi dua komponen yaitu Power Supply DC $12 \mathrm{~V} 5 \mathrm{~A}$ berfungsi sebagai sumber tegangan utama dan penurun tegangan $12 \mathrm{~V}-5 \mathrm{~V}$ sebagai input ke mikrokontroler Arduino Nano dan pompa air DC $12 \mathrm{~V}$. Blok input terdiri dari sensor pH air, sensor suhu, sensor salinitas dan RTC. Sensor $\mathrm{pH}$ air merupakan sensor yang digunakan untuk mengukur nilai keasaman air dalam tambak. Sensor suhu digunakan untuk mengukur nilai suhu air dalam tambak. Sensor salinitas juga merupakan sensor yang digunakan untuk mengukur suatu nilai namun sensor ini digunkan untuk mengukur nilai kadar garam air dalam tambak. Sedangkan untuk RTC digunakan sebagai pewaktu pada alat ini. Blok proses merupakan suatu bagian utama pada alat prototype sistem kendali kualitas air tambak udang. Blok proses juga bisa disebut otak dari rangkaian alat ini dan untuk komponennya sendiri menggunakan mikrokontroller Arduino Nano. Blok output merupakan bagian akhir dari diagram rangkaian ini. Blok output ini sendiri berisi LCD sebagai penampil hasil pembacaan 
nilai dari sensor-sensor alat ini. Buzzer digunakan sebagai alarm jika diketahui nilai bacaan dari sensor buruk. Relay digunakan sebagai saklar pada pompa air. Sedangan untuk pompa air sendiri berfungsi sebagai pengendalian tingkat keasaman air dengan menggunakan cairan $\mathrm{pH}$ up dan $\mathrm{pH}$ down yang disemprotkan pada tambak udang.

Perancangan prototype sistem kendali kualitas air tambak udang terdiri dari perancangan hardware dan software. Untuk mewujudkan perangkat prototype sistem kendali kualitas air diperlukan perancangan yang cermat. Perancangan itu meliputi perancangan mekanik. Perancangan mekanik pada alat ini terdiri dari perancangan alat dan perancangan elektronik.

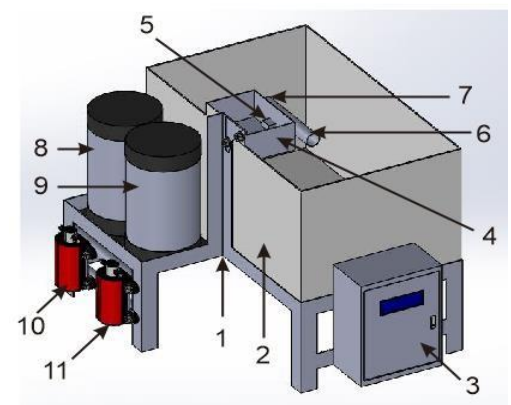

Gambar 3. Desain rancangan alat

Berikut ini adalah keterangan pada Gambar 3, yaitu: (1) frame digunakan sebagai tempat pengendali kualitas air beserta seluruh komponen elektronika pendukung lainnya. Frame harus dibuat kuat dan kokoh untuk menopang seluruh komponen pada alat ini; (2) Akuarium digunakan sebagai pengandaian suatu tambak udang. Akuarium yang digunakan pada alat ini berukuran $60 \times 40 \times 40 \mathrm{~cm}$; (3) Panel box digunakan sebagai tempat komponen elektronika dan harus dirancang sesuai dengan kebutuhan komponen agar aman dari ganguan luar; (4) Box motor servo digunakan sebagai tempat motor servo agar aman dari gangguan luar; (5) Motor servo sebagai penggerak mekanik sensor; Sebuah pipa paralon yang dirancang sebagai wadah sensor-sensor untuk memudahkan dalam proses monitoring, dimana (6) merupakan sensor $\mathrm{pH}$ air dan (7) merupakan sensor salinitas dan suhu air; (8) Wadah cairan
$\mathrm{pH}$ up sebagai tempat cairan $\mathrm{pH}$ up pada akuarium; (9) Wadah cairan $\mathrm{pH}$ down sebagai tempat cairan $\mathrm{pH}$ down pada akuarium; (10) Pompa air 1 digunakan untuk menyedot dan menyemprotkan cairan $\mathrm{pH}$ up pada akuarium; dan (11) Pompa air 2 digunakan untuk menyedot dan menyemprotkan cairan $\mathrm{pH}$ down pada akuarium.

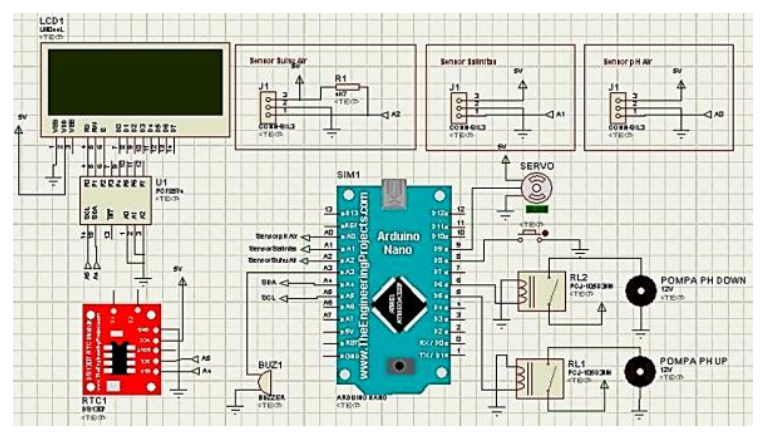

Gambar 4. Rangkaian elektronik

Perancangan elektronik pada alat ini akan disesuaikan dengan kebutuhan input dari tiap komponen elektronik. Gambar 4 merupakan gambar rangkaian secara keseluruhan yang berupa konfigurasi komponen terhadap Arduino Nano. Pada pin A0 dihubungkan ke data dari sensor $\mathrm{pH}$ air. Pin A1 dihubungkan ke sensor Salinitas. Pin A2 dihubungkan ke sensor suhu air. Pin A3 dihubungkan ke buzzer. Pin A4 dan A5 merupakan SDA dan SCL yang dihubungkan ke I2C LCD 20x4 dan RTC. Pin 5 dan 6 dihubungkan ke IN relay. Pin 8 dihubungkan ke push button. Pin 9 dihubungkan ke data motor servo.

Pemrogaman alat yang digunakan adalah software Arduino IDE. Software ini menggunakan bahasa pemrogaman C. Listing program Arduino ini dikenal dengan nama sketch, "void setup()" \{\} dan "void loop() \{\} " merupakan dua buah fungsi dari tiap-tiap sketch. Untuk membuat program Arduino ini dimulai dengan menginstalisasi pin-pin mana saja yang akan digunakan oleh system.

Perancangan perangkat lunak pada alat ini membutuhkan teknik perancangan stuktur pembuatan yang baik. Diagram alur (flowchart) digunakan untuk menggambarkan terlebih dahulu apa yang harus dikerjakan sebelum 
memulai membuat suatu sistem. Gambar 5 merupakan flowchart dari program alat yang akan dibuat.

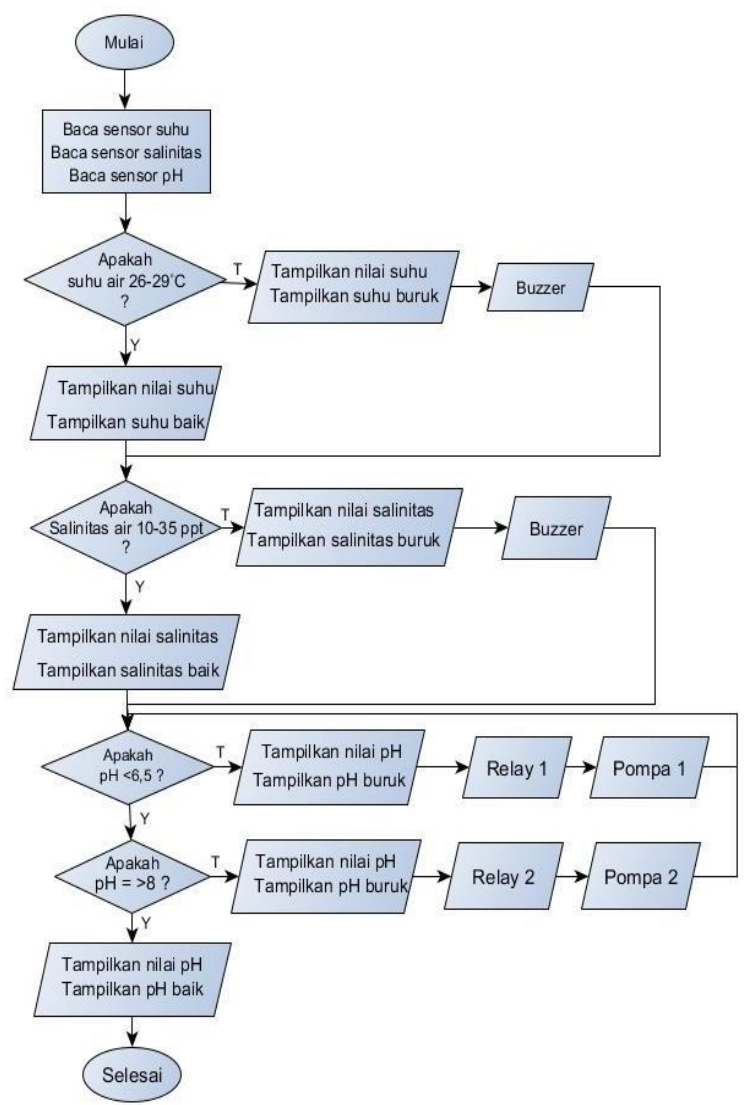

Gambar 5. Flowchart monitoring dan pengendalian kualitas air

Pada pengerjaan perangkat ini diperlukan beberapa tahapan dalam pembuatannya guna menunjang pengerjaan yang lebih efektif dan efisien. Berikut ini adalah tahapan dari proses pembuatannya: (1) menyiapkan alat dan bahan yang dibutuhkan dengan menganalisa kebutuhan baik untuk input, proses maupun output; (2) merancang desain mekanik; (3) merealisasikan rancang bangun mekanik; (4) merancang dan mensimulasikan rangkaian elektronik; (5) mendesain layout PCB dan mencetak PCB dari rangkaian komponen elektronik; (6) merancang dan mengimplementasikan program dari perangkat lunak Arduino IDE; (7) menguji unjuk kerja dari tiap rancang bangun mekanik, rangkaian elektronik dan rancangan perangkat lunak; dan (8) menguji unjuk kerja keseluruhan alat baik berupa rancang bangun mekanik, rangkaian elektronik dan perangkat lunak.
Spesifikasi dari perangkat yang dikembangkan yaitu: (1) menggunakan sumber tegangan $220 \mathrm{VAC}$; (2) kendali sistem dengan Arduino Nano; (3) pembacaan $\mathrm{pH}$, salinitas, dan suhu pada air tambak udang; (4) pengendalian $\mathrm{pH}$ air dengan relay pada pompa air; dan (5) tampilan Pembacaan dengan LCD.

Secara umum, berdasarkan tahapan pengujian, dapat disimpulkan bahwa sistem yang telah dirancang bekerja sebagaimana mestinya, meskipun terdapat error di beberapa rangkaian sensor. Pada pengukuran alat ini, power supply dan modul stepdown dapat bekerja dengan baik dan sesuai dengan yang diharapkan. Tegangan output yang terbaca sesuai dengan kebutuhan walaupun terdapat selisis tegangan antara output yng terbaca dengan tegangan output datasheet. Power supply dan modul stepdown ini memenuhi tegangan kerja pompa air DC yaitu sebesar $12 \mathrm{~V}$ dan mikrokontroller Arduino Nano sebesar 5V. Pengukuran ini dapat dilihat pada Tabel 1.

Tabel 1. Hasil Pengujian Power Supply dan Modul

\begin{tabular}{lccccc}
\multicolumn{5}{c}{ Stepdown } \\
& $\begin{array}{c}\text { Uji } \\
\text { ke- }\end{array}$ & Vout & $\begin{array}{c}\text { Vout } \\
\text { terbaca }\end{array}$ & $\begin{array}{c}\text { Selisih } \\
\text { tegangan }\end{array}$ & Error \\
\hline Power & 1 & $12 \mathrm{~V}$ & $12.2 \mathrm{~V}$ & $0.2 \mathrm{~V}$ & $1.6 \%$ \\
Supply & 2 & $12 \mathrm{~V}$ & $12.2 \mathrm{~V}$ & $0.2 \mathrm{~V}$ & $1.6 \%$ \\
12V/5A & 3 & $12 \mathrm{~V}$ & $12.2 \mathrm{~V}$ & $0.2 \mathrm{~V}$ & $1.6 \%$ \\
Stepdown & 1 & $5 \mathrm{~V}$ & $5 \mathrm{~V}$ & 0 & 0 \\
5V/3A & 2 & $5 \mathrm{~V}$ & $5 \mathrm{~V}$ & 0 & 0 \\
& 3 & $5 \mathrm{~V}$ & $5 \mathrm{~V}$ & 0 & 0 \\
\hline
\end{tabular}

Sensor suhu air DS18b20 dapat bekerja dengan normal. Pada saat sensor ini dicelupkan ke dalam air maka nilai keluarannya kurang lebih sama dengan alat ukur termometer sebagai pembandingnya. Sensor ini memiliki rata-rata error $0.74 \%$ dari 5 kali percobaan. Pengijian ini dapat dilihat pada Tabel 2.

Tabel 2. Hasil Pengujian Sensor Suhu

\begin{tabular}{cccc}
\hline No & DS18b20 $\left({ }^{\circ} \mathrm{C}\right)$ & Termometer $\left({ }^{\circ} \mathrm{C}\right)$ & Error $(\%)$ \\
\hline 1 & 29.15 & 29 & 0.51 \\
2 & 30.36 & 30 & 1.2 \\
3 & 31.25 & 31 & 0.8 \\
4 & 32.33 & 32 & 1.03 \\
5 & 33.05 & 33 & 0.15 \\
\multicolumn{4}{c}{ Rerata Error } \\
\hline
\end{tabular}


Hasil pengujian sensor $\mathrm{pH}$ air $\mathrm{PH}-4520 \mathrm{C}$ dapat dilihat hasil pembacaan pHnya kurang lebih sama dengan alat ukur $\mathrm{pH}$ meter sebagai pembandingnya. Berdasarkan hasil pengujiannya, sensor $\mathrm{pH}$ air $\mathrm{PH}-4520 \mathrm{C}$ memiliki rata-rata error 2.06 dari 5 kali percobaan. Sensor ini secara umum dapat bekerja dengan normal. Pengujian ini dapat dilihat pada Tabel 3.

Tabel 3. Hasil Pengujian sensor $\mathrm{pH}$

\begin{tabular}{cccc}
\hline No & PH-4520 $(\mathrm{pH})$ & $\mathrm{pH}$ meter $(\mathrm{pH})$ & Error $(\%)$ \\
\hline 1 & 6.70 & 6.97 & 3.87 \\
2 & 3.18 & 3.36 & 5.36 \\
3 & 3.03 & 3.05 & 0.66 \\
4 & 10.05 & 10.07 & 0.20 \\
5 & 10.22 & 10.24 & 0.20 \\
\multicolumn{4}{c}{ Rerata Error } \\
\hline
\end{tabular}

Sensor salinitas secara umum dapat bekerja dengan normal. Pada saat sensor ini dicelupkan ke dalam air maka nilai keluarannya kurang lebih sama dengan alat ukur salinometer dan nilai keluarannya akan berubah sesuai dengan keadaan air. Sensor ini memiliki ratarata error 3.60 dari 5 kali percobaan. Pengujian ini dapat dilihat pada Tabel 4.

Tabel 4. Hasil Pengujian Sensor Salinitas

\begin{tabular}{cccc}
\hline No & $\begin{array}{c}\text { Sensor } \\
\text { salinitas (ppt) }\end{array}$ & $\begin{array}{c}\text { Salinometer } \\
(\mathrm{ppt})\end{array}$ & Error (\%) \\
\hline 1 & 3.85 & 3.78 & 1.85 \\
2 & 5.23 & 5.14 & 1.75 \\
3 & 5.52 & 5.89 & 6.28 \\
4 & 6.62 & 6.61 & 0.15 \\
5 & 6.70 & 7.28 & 7.97 \\
\multicolumn{4}{c}{ Rerata Error } \\
\hline
\end{tabular}

Pengukuran untuk pengujian masingmasing sensor dilakukan sebanyak lima kali. Dari hasil tersebut didapatkan rata- rata error untuk sensor suhu air, sensor $\mathrm{pH}$ air dan sensor salinitas berturut-turut adalah $0.74 \%, 2.06 \%$, dan $3.60 \%$. Ketiga nilai error tersebut kurang dari $10 \%$. Pengukuran dengan nilai error kurang dari $10 \%$ akan dianggap sebagai keberhasilan pengujian [7].

Pompa air dapat bekerja dengan baik dan normal sesuai dengan yang diharapkan. Ketika relay mendapat sinyal $\mathrm{HIGH}$ dari mikrokontroler, pompa air mendapat sinyal tegangan 12 volt dari power supply maka pompa akan aktif dan menyemprotkan cairan $\mathrm{pH}$. Sedangkan ketika relay mendapat sinyal LOW maka pompa air akan tertutup atau tidak aktif karena tidak mendapat tegangan 12 volt. Berdasarkan hasil pengujian ini maka pompa dan relay dapat berfungsi dengan baik. RTC dapat bekerja dengan baik dan normal sesuai dengan yang diharapkan. RTC dapat mengirimkan data waktu yang cukup akurat ke mikrokontroler. Terdapat perbedaan waktu selama 1 menit. Hasil pengujian RTC dapat dilihat pada Tabel 5 .

Tabel 5. Hasil Pengujian RTC

\begin{tabular}{ccc}
\hline No & Waktu laptop & Waktu RTC \\
\hline 1 & 21.43 & 21.44 \\
2 & 21.46 & 21.47 \\
3 & 21.48 & 21.49 \\
4 & 21.52 & 21.53 \\
5 & 21.56 & 21.57 \\
\hline
\end{tabular}

Pengujian unjuk kerja dilakukan pada volume akuarium $96.000 \mathrm{~cm}^{3}$ dengan dua bagian pengujian. Pengujian pertama adalah bagian monitoring dan untuk pengujian kedua adalah bagian pengendalian. Pada pengujian pertama sensor suhu, $\mathrm{pH}$ dan salinitas air akan membaca nilai dari kualitas air yang terdapat pada akuarium. Jika kualitas air buruk atau tidak sesuai dengan kriteria air baik untuk pertumbuhan udang maka buzzer akan aktif. Tabel 6 dan 7 menunjukkan hasil pengujian unjuk kerja.

Tabel 6. Pengujian unjuk kerja alat bagian

\begin{tabular}{clccc}
\multicolumn{5}{c}{ monitoring } \\
\hline No & & Uji ke- & Buzzer & LCD \\
\hline 1 & Sensor suhu & 1 & OFF & 29 \\
& air $\left({ }^{\circ} \mathrm{C}\right)$ & 2 & OFF & 30 \\
& & 3 & ON & 35 \\
2 & Sensor $\mathrm{pH}$ & 1 & ON & 3.03 \\
& air $(\mathrm{pH})$ & 2 & OFF & 7.03 \\
& & 3 & ON & 10.05 \\
3 & Sensor & 1 & OFF & 23 \\
& salinitas air & 2 & OFF & 25 \\
& (ppt) & 3 & ON & 5 \\
\hline
\end{tabular}

Tabel 7. Pengujian unjuk kerja alat bagian pengendaliaN

\begin{tabular}{cccccc}
\hline No & & Uji ke- & $\mathrm{pH}$ & Pompa 1 & Pompa 2 \\
\hline 1 & $\mathrm{pH}$ up & 1 & 3.18 & Terbuka & Tertutup \\
& & 2 & 10.05 & Tertutup & Terbuka \\
2 & $\mathrm{pH}$ & 1 & 3.03 & Tertutup & Terbuka \\
& down & 2 & 10.22 & Terbuka & Tertutup \\
\hline
\end{tabular}


Pada pengujian pengendalian $\mathrm{pH}$ air, jika proses monitoring $\mathrm{pH}$ air buruk atau tidak memenuhi kriteria air baik untuk udang maka pompa air akan menyemprotkan cairan $\mathrm{pH}$ up ataupun $\mathrm{pH}$ down ke akuarium. Cairan $\mathrm{pH}$ up akan disemprotkan ketika nilai $\mathrm{pH}$ air <6.5. Sedangkan cairan $\mathrm{pH}$ down akan disempotkan ketika nilai $\mathrm{pH}$ air $>8$. Lama waktu penyemprotan cairan $\mathrm{pH}$ masing-masing adalah 2 detik dan mengeluarkan cairan sebanyak kurang lebih $10 \mathrm{ml}$. Cairan $\mathrm{pH}$ up yang digunakan pada pengujian memiliki $\mathrm{pH} 11$ sedangkan $\mathrm{pH}$ down memiliki $\mathrm{pH} 3$. Pengujian dilakukan di akuarium dengan $\mathrm{pH} 6$ yang dikatakan buruk maka untuk mengatasinya dibutuhkan cairan $\mathrm{pH}$ up sebanyak $0.0864 \mathrm{~L}$ agar pH menjadi 7 yang diperoleh dari perhitungan di bawah ini, dengan $\mathrm{K}$ adalah tetapan kesetimbangan air, $\left[\mathrm{H}^{+}\right]$adalah molaritas ion $\mathrm{H}^{+}$ dan $\left[\mathrm{OH}^{-}\right]$adalah molaritas ion $\mathrm{OH}^{-}$. Perhitungan tersebut mengacu pada Partana [8].

$$
\begin{aligned}
& K=\frac{\left[\mathrm{H}^{+}\right]\left[\mathrm{OH}^{-}\right]}{\left[\mathrm{H}_{2} \mathrm{O}\right]} \\
& \mathrm{K}=\left[\mathrm{H}_{2} \mathrm{O}\right]=\left[\mathrm{H}^{+}\right]\left[\mathrm{OH}^{-}\right] \\
& \mathrm{K} \omega=\left[\mathrm{H}^{+}\right]\left[\mathrm{OH}^{-}\right] \\
& {\left[\mathrm{H}^{+}\right]=10^{-6} \mathrm{M}}
\end{aligned}
$$

Jumlah mol H $\mathrm{H}^{+}=10^{-6} \frac{\mathrm{mol}}{\mathrm{L}} \times 96 \mathrm{~L}=96 \times 10^{-6} \mathrm{~mol}$

Jumlah mol $\mathrm{H}^{+}$pada $\mathrm{pH} 7$

$\left[\mathrm{H}^{+}\right]=10^{-7}$

$$
\begin{aligned}
\text { Jumlah mol } \mathrm{H}^{+} & =10^{-7} \times(96+\mathrm{V}) \\
& =96 \times 10^{-7}+10^{-7} \mathrm{~V} \mathrm{~mol}
\end{aligned}
$$

Jumlah mol $\mathrm{H}^{+}$pada $\mathrm{pH} 11$

$$
\begin{aligned}
& {\left[\mathrm{H}^{+}\right]\left[\mathrm{OH}^{-}\right]=\mathrm{K} \omega} \\
& {\left[\mathrm{H}^{+}\right]=\frac{10^{-14}}{10^{-3}}=10^{-11}} \\
& {\left[\mathrm{OH}^{-}\right]=10^{-3}} \\
& \text { mol OH}=10^{-3} \mathrm{~V} \\
& \text { mol yang bereaksi dengan }\left[\mathrm{OH}^{-}\right] \\
& \text {mol pH6 }- \text { mol pH7 } \\
& 96 \times 10^{-6} \mathrm{~mol}-\left(96 \times 10^{-7}+10^{-7} \mathrm{~V}\right) \mathrm{mol}=10^{-3} \mathrm{~V} \\
& 0.0000864=10^{-3} \mathrm{~V} \\
& \mathrm{~V}=\frac{0.0000864}{10^{-3}}=0.0864 \mathrm{~L}
\end{aligned}
$$

Tambak udang biasanya memiliki luas $200 \mathrm{~m}^{3}$. Jika sebuah tambak memiliki pH 6 yang

\begin{tabular}{|c|c|c|c|}
\hline \multicolumn{4}{|c|}{ Cairan $\mathrm{pH}$ up Cairan $\mathrm{pH}$ down } \\
\hline pH awal & $\begin{array}{c}\text { dengan } \mathrm{pH} \\
\text { (liter) }\end{array}$ & $\begin{array}{c}\text { dengan pH } 3 \\
\text { (liter) }\end{array}$ & $\mathrm{pH}$ akhir \\
\hline 6 & 0.0864 & - & 7 \\
\hline 8.5 & - & 0.0432 & 8 \\
\hline 5.5 & 0.1296 & - & 7 \\
\hline
\end{tabular}
dikatakan buruk maka untuk mengatasinya dibutuhkan cairan $\mathrm{pH}$ up sebanyak $180 \mathrm{~L}$ agar $\mathrm{pH}$ menjadi 7 yang diperoleh dari perbandingan hasil pengujian akuarium dan volume tambak sebenarnya seperti dibawah ini,

\begin{tabular}{|c|c|c|c|}
\hline 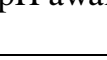 & (liter) & (liter) & 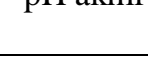 \\
\hline 6 & 180 & - & 7 \\
\hline 8.5 & - & 90 & 8 \\
\hline 5.5 & 270 & - & 7 \\
\hline
\end{tabular}
dengan $\mathrm{V}$ akuarium adalah $96.000 \mathrm{~cm}^{3}=93 \mathrm{dm}^{3}$ dan V tambak $200 \mathrm{~m}^{3}=200000 \mathrm{dm}^{3}$.

$$
\begin{gathered}
\frac{V_{\text {akuarium }}}{V_{\text {tambak }}}=\frac{96}{200000}=\frac{3}{6250} \\
\frac{0.0864}{V_{\text {tambak }}}=\frac{3}{6250} \\
V_{\text {tambak }}=\frac{0.0864 \times 6250}{3}=180 \mathrm{~L}
\end{gathered}
$$

Perbandingan antara volume cairan $\mathrm{pH}$ up tambak dengan $\mathrm{pH}$ up akuarium untuk memiliki perubahan $\mathrm{pH}$ sebanyak 1 adalah 180L : 0.0864L. Berikut ini adalah simulasi kontrol pH.

Tabel 8. Perhitungan volume $\mathrm{pH}$ air pada akuarium (volume 96 liter)

Tabel 9. Perhitungan volume $\mathrm{pH}$ air pada tambak (volume 200000 liter)

Cairan $\mathrm{pH}$ up Cairan $\mathrm{pH}$ down

pH awal dengan pH 11 dengan pH 3 pH akhir

\section{SIMPULAN}

Pembuatan prototype sistem kendali kualitas air tambak udang yaitu dengan menggunakan perangkat keras yang mampu menopang semua komponen elektronika maupun komponen pendukung lainnya. Untuk perancangan perangkat lunak menggunakan Arduino IDE yang berfungsi untuk memprogram mikrokontroller Arduino Nano. Alat ini dapat mempermudah dan meringankan pekerjaan 
petambak udang dalam pengecekan kualitas air secara berkala. Hasil unjuk kerja dari prototype sistem kendali kualitas air tambak udang ini secara keseluruhan bekerja dengan baik. Semua komponen dapat digunakan dengan semestinya. Terdapat error dalam pembacaan sensor namun secara umum sensor dapat bekerja dengan normal. LCD dapat menampilkan tampilan nilai dari pembacaan sensor dengan baik.

Berdasarkan hasil yang telah dibuat, ternyata ditemukan banyak kekurangan dalam pengerjaan alat ini. Untuk memperkecil atau mengurangi kekurangan ini maka perlu upaya lanjutan dalam pembuatan alat ini yang berupa: (1) penambahan kapasitas wadah cairan $\mathrm{pH}$ up dan $\mathrm{pH}$ down; (2) pembuatan sumber daya menggunakan panel surya untuk daya cadangan ketika listrik PLN mati; dan (3) penambahan komponen yang dapat memonitoring dan mengendalikan kualitas air dari jarak jauh.

\section{DAFTAR PUSTAKA}

[1] R. J. Permana, "Penerapan HACCP pada pembekuan Udang BekuTanpa Kepala (headless) di PT. Satu Tiga Enam Delapan Banyuwangi Jawa Timur,” 2007.

[2] Suhana, "Jokowi dan Ekonomi Udang Indonesia," Kompas.com, 2017. [Online]. Available: https://ekonomi.kompas.com/read/2017/11/07/1 42435426/jokowi-dan-ekonomi-udangindonesia?page $=$ all.

[3] P. A. Pudyastuti, H. Sambodo, and K. Windhani, "Analisis Daya Saing Ekspor Komoditas Udang Indonesia di Pasar Eropa Tahun 2008-2016," in Seminar Nasional dan Call for Paper Sustainable Competitive Advantage (SCA), 2018.

[4] E. A. Hendrajat and M. Mangampa, "Budidaya Udang Vannamei Pola Tradisional Plus Di Kabupaten Maros, Sulawesi Selatan," Media Akuakultur, vol. 2, no. 2, pp. 1-4, 2007.

[5] F. R. Putra and A. Manan, "Monitoring Kualitas Air pada Tambak Pembesaran Udang Vannamei (Litopenaeus vannamei) di Situbondo, Jawa Timur," J. Ilm. Perikan. dan Kelaut., vol. 6, no. 2, pp. 137-141, 2014.

[6] D. Adiwijaya, K. Coco, and Supito, Teknis Operasional Budidaya Udang Ramah Lingkungan. Jepara: Departemen Kelautan dan Perikanan. Derektorat Jendral Perikanan Budidaya. Balai Besar Pengembangan Air Payau, 2001.

[7] T. J. R, An introduction to error analysis. University Science Books: Susanna Tadlock, 1997.

[8] C. F. Partana, Mari belajar kimia 2. Jakarta: Departemen Pendidikan Nasional, 2009. 